\title{
Impact of Tropospheric Delay Gradients on Total Tropospheric Delay and Precise Point Positioning
}

\author{
Mohamed Elsobeiey ${ }^{1}$, Mohamed El-Diasty ${ }^{1,2}$ \\ ${ }^{1}$ Department of Hydrographic Surveying, Faculty of Maritime Studies, King Abdulaziz University, \\ Jeddah, KSA \\ ${ }^{2}$ Engineering Department of Public Works, Faculty of Engineering, Mansoura University, Mansoura, Egypt \\ Email:melsobeiey@kau.edu.sa,mkandeel@kau.edu.sa
}

Received 3 April 2016; accepted 15 May 2016; published 18 May 2016

Copyright (c) 2016 by authors and Scientific Research Publishing Inc.

This work is licensed under the Creative Commons Attribution International License (CC BY). http://creativecommons.org/licenses/by/4.0/

(c) () O) Open Access

\begin{abstract}
GPS signals are electromagnetic waves that are affected by the Earth's atmosphere. The Earth's atmosphere can be categorized, according to its effect on GPS signals, into the ionosphere (ionospheric delay) and neutral atmosphere (tropospheric delay). The first-order ionospheric delay can be eliminated by linear combination of GPS observables on different frequencies. However, tropospheric delay cannot be eliminated because it is frequency-independent. The total tropospheric delay can be divided into three components. The first is the dry component, the second part is the wet component, and the third part is the horizontal gradients which account for the azimuthal dependence of tropospheric delay. In this paper, the effect of modeling tropospheric gradients on the estimation of the total tropospheric delay and station position is investigated. Long session, one month during January 2015 , of GPS data is collected from ten randomly selected globally distributed IGS stations. Two cases are studied: the first case, the coordinates of stations are kept fixed to their actual values and the tropospheric delay is estimated twice, with and without tropospheric gradients. In the second case, the station position is estimated along with the total tropospheric delay with and without tropospheric gradients. It is shown that the average bias of the estimated total tropospheric delay when neglecting tropospheric gradients ranges from $\mathbf{- 1 . 7 2} \mathbf{~ m m}$ to $2.14 \mathrm{~mm}$ while the average bias when estimating gradients are $-0.898 \mathrm{~mm}$ to $1.92 \mathrm{~mm}$ which means that the bias is reduced by about $30 \%$. In addition, the average standard deviation of the bias is $4.26 \mathrm{~mm}$ compared with $4.52 \mathrm{~mm}$ which means that the standard deviation is improved by about $6 \%$.
\end{abstract}

\section{Keywords}

Precise Point Positioning, Electromagnetic Waves, Tropospheric Delay, Tropospheric Gradients 


\section{Introduction}

The tropospheric layer represents the lower part of the atmosphere, which extends up to $50 \mathrm{~km}$ from the earth's surface [1]. Tropospheric layer causes delay to the signal, which is known as tropospheric delay. Unfortunately, the effect of troposphere is equal on both code and carrier phase. This is why tropospheric effect cannot be eliminated while maintaining geometry using linear combinations between observables. Tropospheric delay depends on pressure, humidity, and temperature along the propagation path of the signal. Generally, tropospheric delay is minimum when the satellite is at the user's zenith, and is maximum when the satellite is near the user's horizon.

Typically, tropospheric delay can be divided into two components, namely, dry and wet component. The dry component represents $90 \%$ of the total delay, while the wet component represents $10 \%$ of the total tropospheric delay [2]. However, the horizontal gradients are usually neglected. The main reason of the wet tropospheric delay is the water vapor in the lower part of the tropospheric layer, $11 \mathrm{kms}$ from sea level, and it contains most of the water vapor. Modeling of the wet delay component is difficult because of the water vapor density is variable with both position and time. The average total zenith troposphere delay varies between 2.3 and $2.6 \mathrm{~m}$ [3]. Unlike the dry component, the wet component is highly correlated with the total tropospheric delay [4]; hence the wet component is highly correlated with the station height [5]. The tropospheric delay components (dry and wet) are usually modeled at zenith and then mapped to the corresponding satellite elevation angle using an elevation angle dependent mapping function as follows [6]:

$$
\begin{aligned}
& T=T_{Z, d} M_{d}+T_{z, w} M_{w}+\left[G_{N} \cos (\alpha)+G_{E} \sin (\alpha)\right] M_{g} \\
& M_{g}=\frac{1}{\sin (E) \tan (E)+0.0032}
\end{aligned}
$$

where $T$ is the total zenith tropospheric delay, $T_{z, d}$ is the zenith dry component of total zenith tropospheric delay, $T_{z, w}$ is the zenith wet component of total zenith tropospheric delay, $M_{d}$ is the dry mapping function, $M_{w}$ is the wet mapping function, $G_{N}$ and $G_{E}$ are the northern and eastern horizontal delay gradients, $M_{g}$ is the tropospheric gradient mapping function, $\alpha$ is the satellite azimuth, and $E$ is the satellite elevation angle. Equation (1) divided the total tropospheric delay into three components. The first is the dry component, the second is the wet component, and the third part accounts for the azimuthal dependence of tropospheric delay with the introduction of the horizontal gradients $G_{N}$ and $G_{E}$ in the North-South and East-West directions, respectively [7]. Different models are available to compute the zenith tropospheric delay (dry and wet components). Tropospheric models include Saastamoinen model [8], Davis et al. model [9], Baby et al. model [10], Hopfield model [11], and NOAA tropospheric model [4]. Mapping functions, on the other hand, include Chao mapping function [12], Davis mapping function [9], Herring mapping function (MTT) [13], Niell mapping function (NMF) [14], and Vienna mapping function (VMF1) [15]. For more details about other tropospheric models and mapping functions, refer to [16] and [17]. This paper is organized to cover different aspects about tropospheric delay, tropospheric gradients, and precise point positioning. Section 2 introduces the PPP mathematical model. Section 3 is devoted to describing the data used in this paper. Sections 4 and 5 cover the impact of tropospheric gradients on total tropospheric delay estimation and PPP solution, respectively. Section 6 summarizes the main paper conclusions.

\section{PPP Mathematical Model}

The mathematical models of GPS observables can be summarized as follows [18]:

$$
\begin{aligned}
& P_{1}=\rho+c\left(d t_{r}-d t_{s}\right)+T+I_{1}+\varepsilon_{P 1} \\
& P_{2}=\rho+c\left(d t_{r}-d t_{s}\right)+T+I_{2}+\varepsilon_{P 2} \\
& \Phi_{1}=\rho+c\left(d t_{r}-d t_{s}\right)+T-I_{1}+\lambda_{1} N_{1}+\varepsilon_{\Phi 1} \\
& \Phi_{2}=\rho+c\left(d t_{r}-d t_{s}\right)+T-I_{2}+\lambda_{2} N_{2}+\varepsilon_{\Phi 2}
\end{aligned}
$$

where $P_{1}$ and $P_{2}$ are the pseudorange (code) measurements on $L_{1}$ and $L_{2}$, respectively; $\Phi_{1}$ and $\Phi_{2}$ are the car- 
rier-phase measurements on $L_{1}$ and $L_{2}$, respectively, scaled to distance (m); $d t_{s}$ and $d t_{r}$ are the satellite and receiver clock errors, respectively; $\lambda_{1}$ and $\lambda_{2}$ are the corresponding wavelengths for carrier phase frequencies $L_{1}$ and $L_{2}$, respectively; $N_{1}$ and $N_{2}$ are the ambiguity integer numbers of $L_{1}$ and $L_{2}$ ambiguities, respectively; $c$ is the speed of light in vacuum ( $\mathrm{m} / \mathrm{sec}) ; \rho$ is the true geometric distance between satellite antenna phase center and receiver antenna phase center at reception time (m); $I_{1}$ and $I_{2}$ are the $L_{1}$ and $L_{2}$ ionospheric delay, respectively; and $\varepsilon_{P 1}, \varepsilon_{P 2}, \varepsilon_{\Phi 1}, \varepsilon_{\Phi 2}$ are the unmodeled errors including residual orbital error, hardware delay, and multipath effect.

The first-order ionosphere free linear combination can be formed as follows:

$$
\begin{aligned}
& P_{3}=\xi_{1} P_{1}-\xi_{2} P_{2}, \Phi_{3}=\xi_{1} \Phi_{1}-\xi_{2} \Phi_{2} \\
& P_{3}=\rho+c\left(d t_{r}-d t_{s}\right)+T+\varepsilon_{P 3} \\
& \Phi_{3}=\rho+c\left(d t_{r}-d t_{s}\right)+T+\lambda_{3} N_{3}+\varepsilon_{\Phi 3}
\end{aligned}
$$

where $P_{3}$ and $\Phi_{3}$ are the first-order ionosphere-free code and carrier phase combinations, $\varepsilon_{P 3}$ and $\varepsilon_{\Phi 3}$ are the first-order ionosphere-free combination of $\varepsilon_{P 1}$ and $\varepsilon_{P 2}$ and $\varepsilon_{\Phi 1}$ and $\varepsilon_{\Phi 2}$, respectively; $\lambda_{3}=c /\left(f_{1}^{2}-f_{2}^{2}\right)$, $\xi_{1}=f_{1}^{2} /\left(f_{1}^{2}-f_{2}^{2}\right), \quad \xi_{2}=f_{2}^{2} /\left(f_{1}^{2}-f_{2}^{2}\right)$, and $N_{3}=\left(f_{1} N_{1}-f_{2} N_{2}\right)$.

Total tropospheric delay can be estimated from Equations (7) and (8) either considering tropospheric gradients or neglecting the tropospheric gradients. This paper examines the effect of tropospheric gradients on the total troposphere estimation and on PPP solution. In the first case, the coordinates of stations are kept fixed to their actual values and the tropospheric delay is estimated twice, with and without tropospheric gradients. In the second case, the station position is estimated along with the total tropospheric delay.

\section{Data Description}

One month of GPS data from a global network consisting of ten randomly selected IGS stations is used (Figure 1). IGS precise orbit and IGS precise clock corrections are used for satellite coordinates and satellite clock error, respectively. Tropospheric corrections are accounted for using the Hopfield model [11] and global mapping function is used for mapping the zenith tropospheric delays (wet and dry) to each satellite-specific elevation angle. The IGS tropospheric files are used as references to compare with whenever required. All other errors, including relativity, carrier phase windup, Earth tides, sagnac, and ocean loading were accounted for using existing models with high accuracy (see e.g., Kouba [5]).

\section{Impact of Tropospheric Gradients Estimation on Total Tropospheric Delay}

To investigate the effect of tropospheric gradients estimation on the total tropospheric delay, the coordinates of

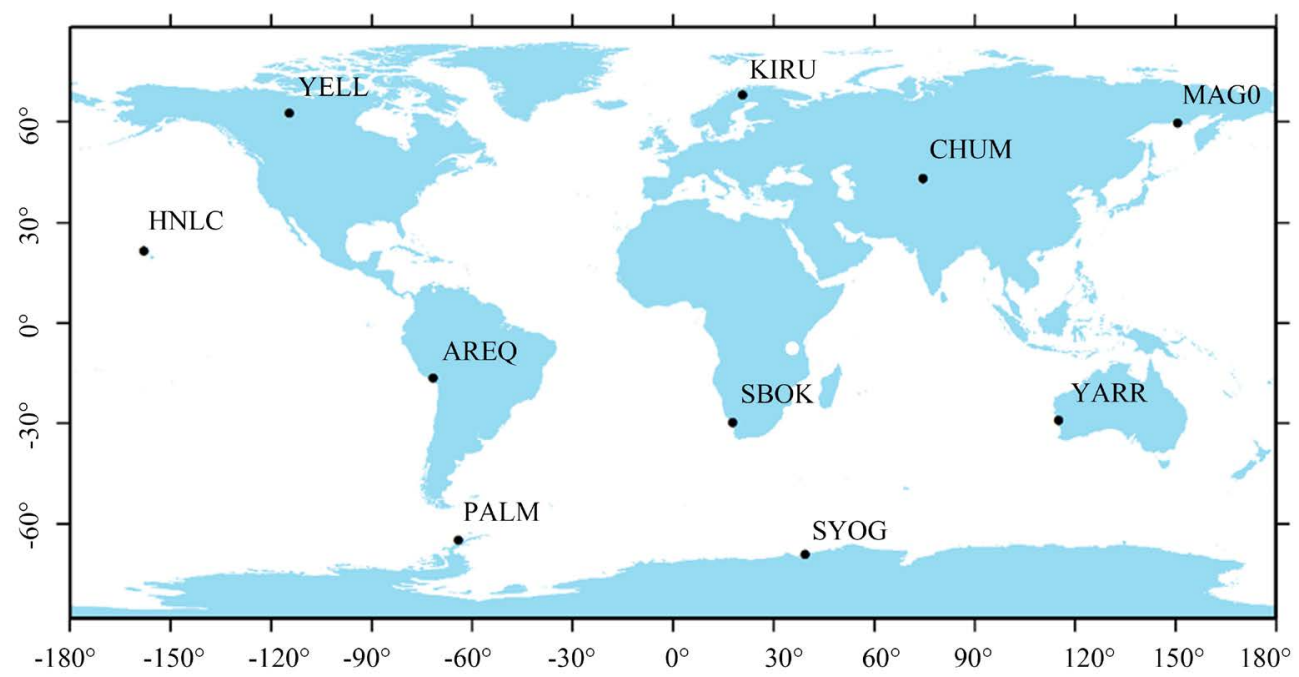

Figure 1. GPS stations used to study tropospheric gradients effect. 
stations are held fixed to their actual values during the processing. The tropospheric error is modelled according to Equations (1) and (2). The estimated total tropospheric delay is compared with the IGS published values. Figure 2 and Figure 3 show the estimated total tropospheric delay when the tropospheric gradients are considered and when it is neglected compared with the IGS published total tropospheric delay.

As seen in Figure 2 and Figure 3, the PPP-based estimated total tropospheric delay is comparable with the IGS published values. However, there is a bias in both cases. To study the bias of the estimated total tropospheric delay, the difference between the IGS published values and the estimated values are computed as seen in Figure 4 and Figure 5 for both stations as examples.

Figure 4 and Figure 5 show that modeling tropospheric gradients reduces the error in the estimated total tropospheric delay. Moreover, the bias in the estimated total tropospheric delay is reduced when modeling the tropospheric gradients. Table 1 summarizes the bias and the corresponding standard deviation (STD) in the estimated total tropospheric delay for all stations.

As seen in Table 1, the average bias of the estimated total tropospheric delay when neglecting tropospheric gradients ranges from $-1.72 \mathrm{~mm}$ to $2.14 \mathrm{~mm}$ while the average bias when estimating gradients are $-0.898 \mathrm{~mm}$ to $1.92 \mathrm{~mm}$ which means that the bias is reduced by about $30 \%$. Moreover, the average standard deviation of the bias is $4.26 \mathrm{~mm}$ compared with $4.52 \mathrm{~mm}$ which means that the standard deviation is improved by about $6 \%$.

\section{Effect of Tropospheric Gradients on PPP Solution}

To investigate the effect of tropospheric gradients on PPP solution, hourly data during January 2015 of the same stations is used. The coordinates are estimated twice, when neglecting the tropospheric gradients and when estimating the tropospheric gradients along with other parameters. Figures 6-11 show latitude, longitude, and ellipsoidal height error for RAMO and KIRU IGS stations in both cases as examples.

Our results showed that estimating the tropospheric gradients improves the estimated coordinates for all stations. Generally, the improvement in the height coordinates is much more than the improvement in the horizontal coordinates (latitude and longitude). Coordinates solution is almost the same for the first 10 minutes till the tropospheric parameters are separated from other unknown parameters. However, after the first 10 minutes the solution behaves better when estimating the tropospheric gradients. Table 2 summarizes the effect of tropos-

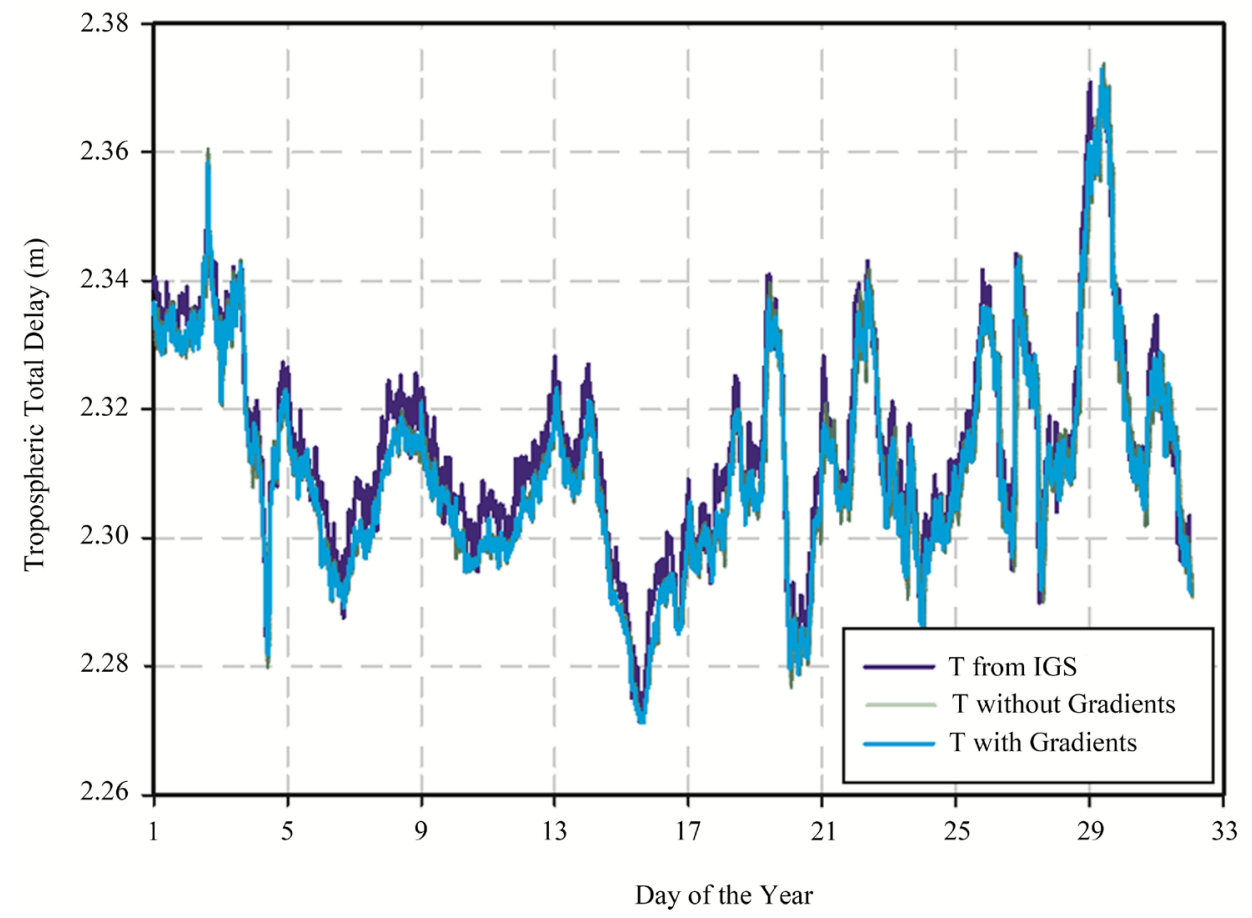

Figure 2. Impact of neglecting tropospheric gradients on total tropospheric delay estimation at PALM IGS station. 


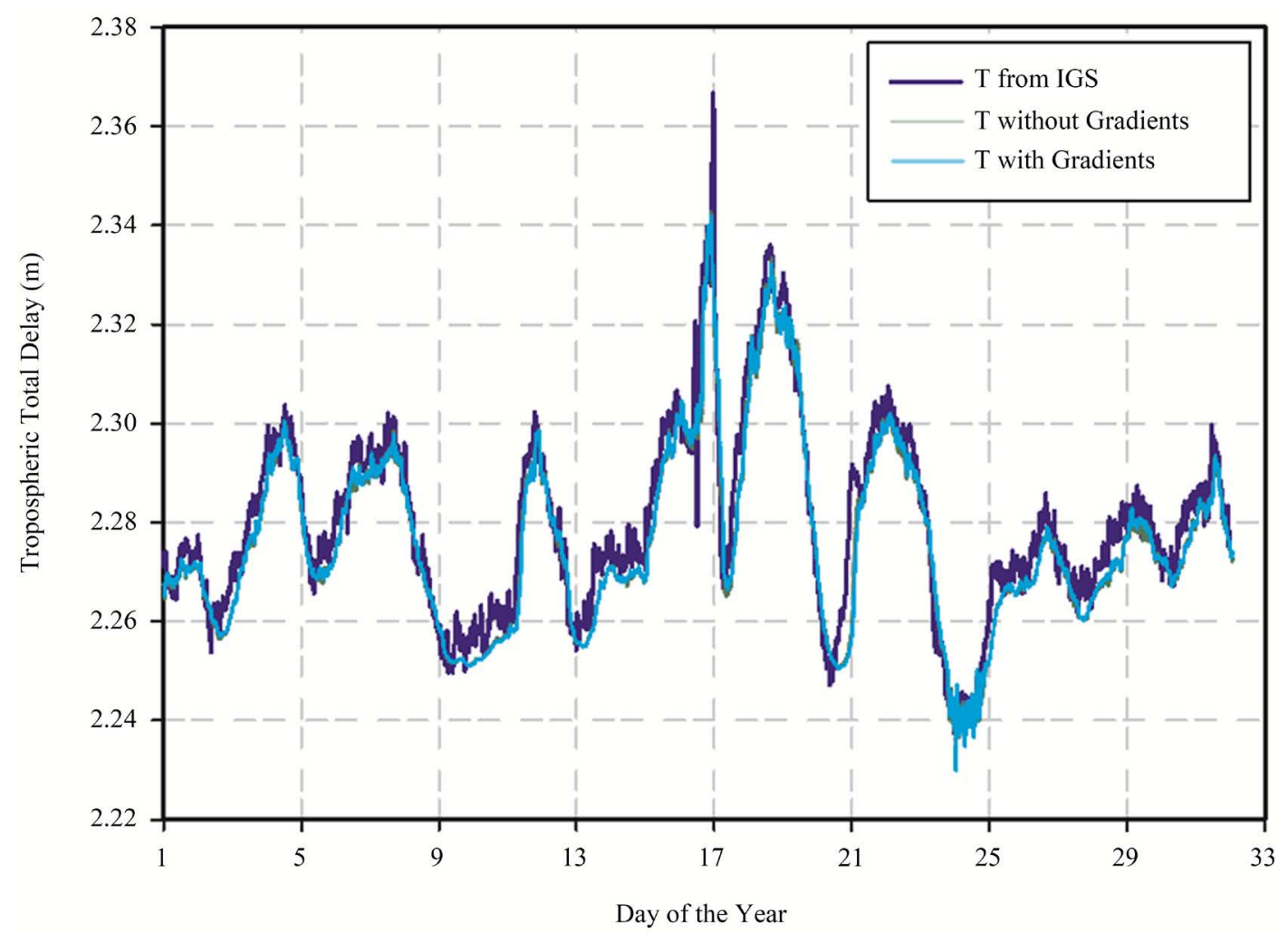

Figure 3. Impact of neglecting tropospheric gradients on total tropospheric delay estimation at SYOG IGS station.

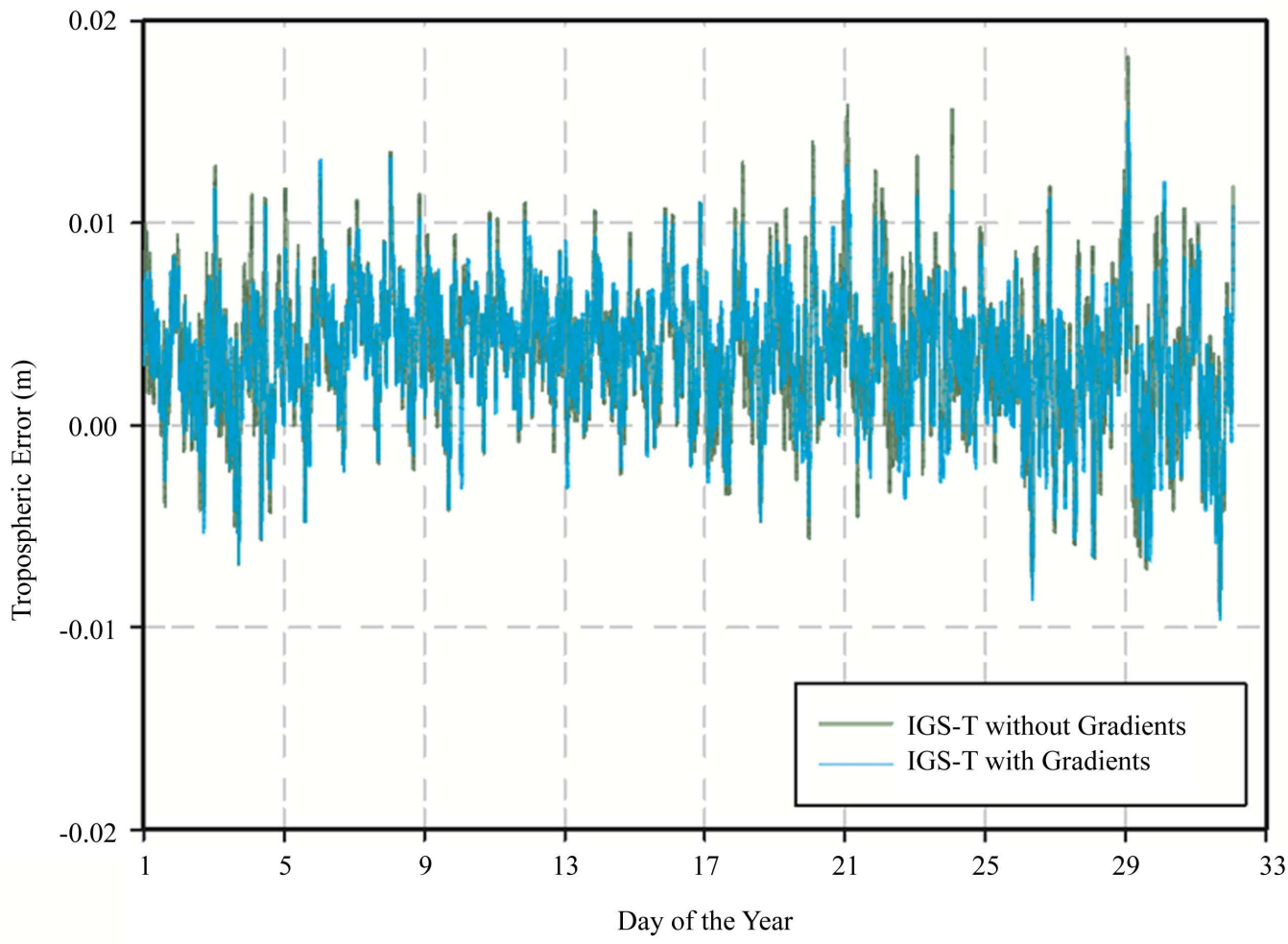

Figure 4. Estimated total tropospheric delay error at PALM IGS station. 


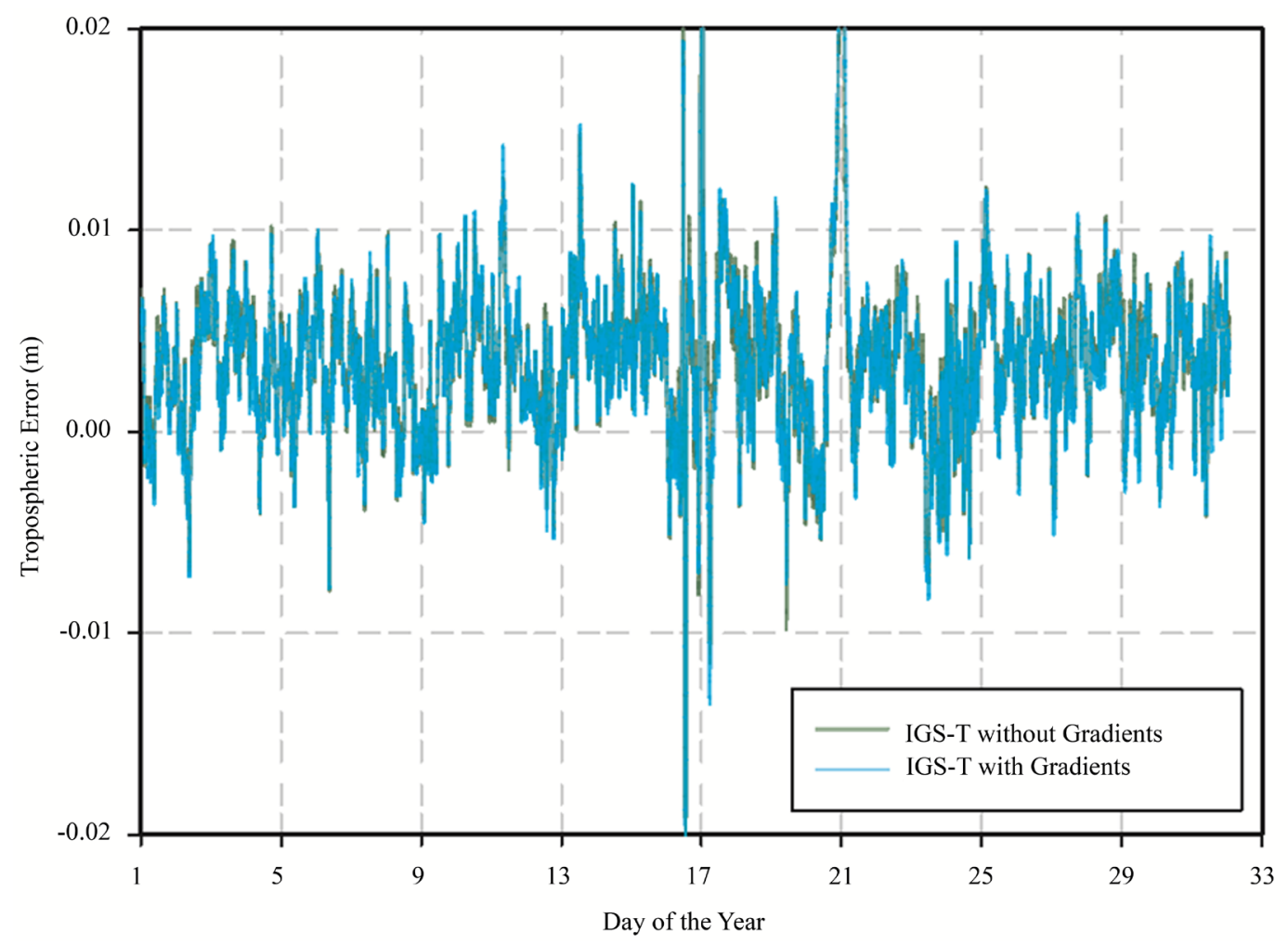

Figure 5. Estimated total tropospheric delay error at SYOG IGS station.

Table 1. Effect of tropospheric gradients on the estimated total tropospheric delay.

\begin{tabular}{ccccc}
\hline \multirow{2}{*}{ Station Name } & \multicolumn{2}{c}{ Without Tropospheric Gradients } & \multicolumn{2}{c}{ With Tropospheric Gradients } \\
\cline { 2 - 4 } & Bias $(\mathrm{mm})$ & STD $(\mathrm{mm})$ & Bias $(\mathrm{mm})$ & STD (mm) \\
AREQ & -2.83 & 5.03 & -0.73 & 4.18 \\
CHUM & -0.38 & 5.24 & -0.23 & 5.24 \\
HNLC & 0.86 & 4.21 & 1.9 & 4.15 \\
KIRU & 0.43 & 4.36 & 0.70 & 3.64 \\
MAG0 & 2.40 & 3.57 & 2.33 & 3.08 \\
PALM & 3.39 & 3.29 & 3.36 & 6.06 \\
SBOK & -2.44 & 6.45 & -1.73 & 4.19 \\
SYOG & 3.61 & 4.03 & 3.47 & 4.64 \\
YARR & -1.22 & 5.28 & 0.23 & 3.37 \\
YELL & 0.91 & 3.48 & 1.41 & 4.26 \\
Average & $-1.72 / 2.14$ & 4.52 & $-0.898 / 1.92$ & \\
\hline
\end{tabular}

pheric delay estimation on the root-mean-square (RMS) of the estimated coordinates.

\section{Conclusion}

In this paper, one month of GPS data collected from ten IGS stations is used to investigate the effect of modeling tropospheric gradients on the estimation of the total tropospheric delay and station position. In the first case, 


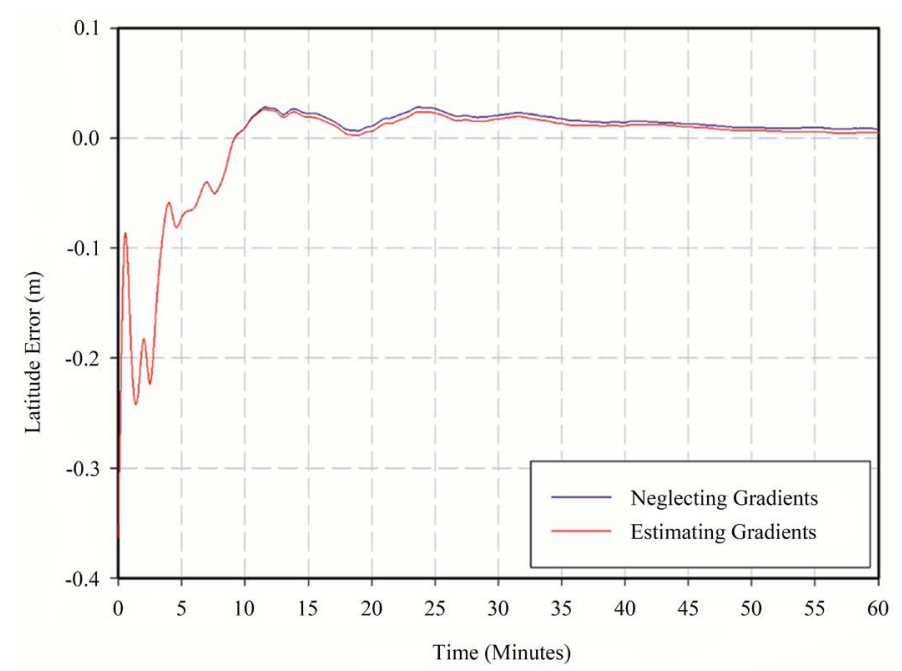

Figure 6. Effect of tropospheric gradients on latitude errors at RAMO IGS station.

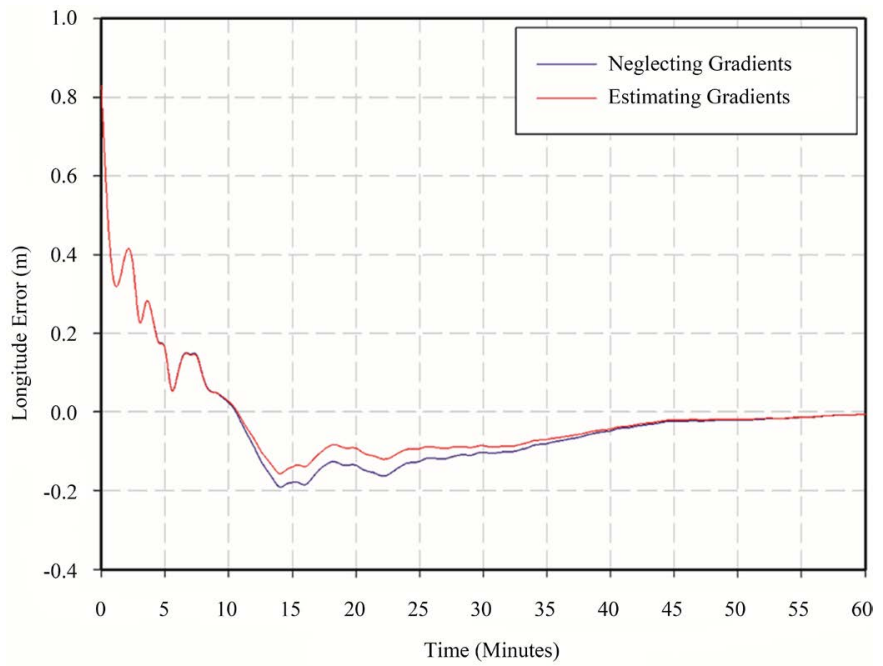

Figure 7. Effect of tropospheric gradients on longitude errors at RAMO IGS station.

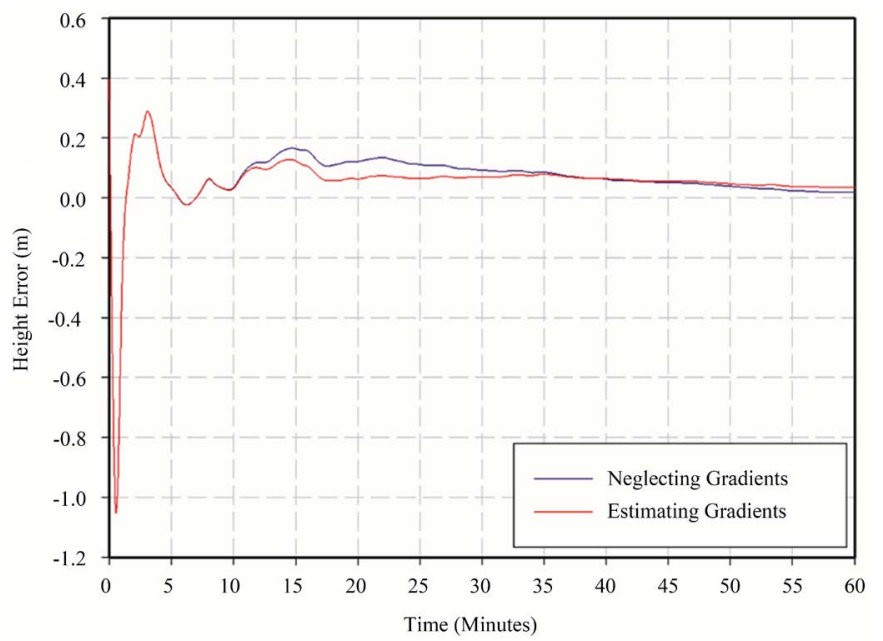

Figure 8. Effect of tropospheric gradients on height errors at RAMO IGS station. 


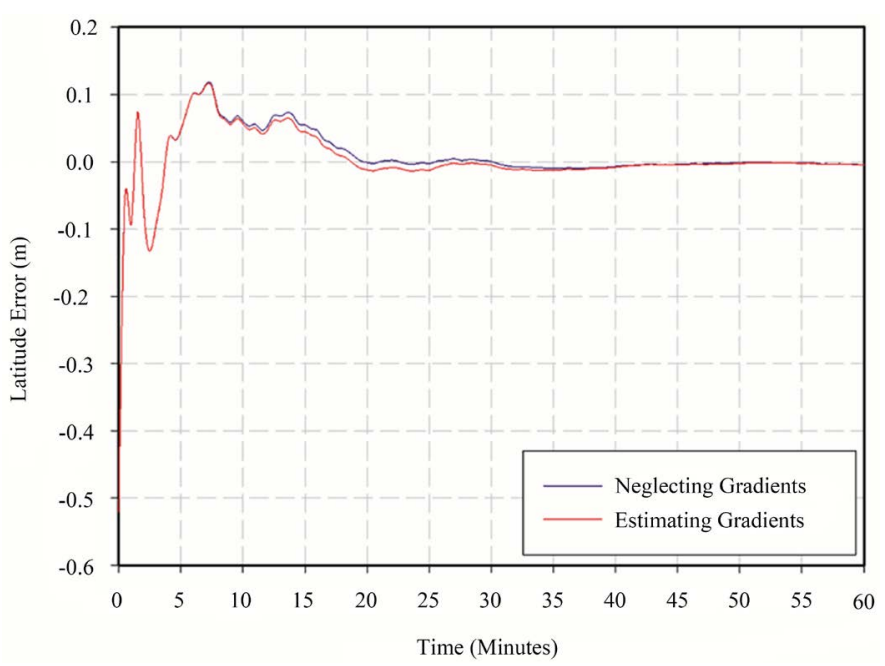

Figure 9. Effect of tropospheric gradients on latitude errors at KIRU IGS station.

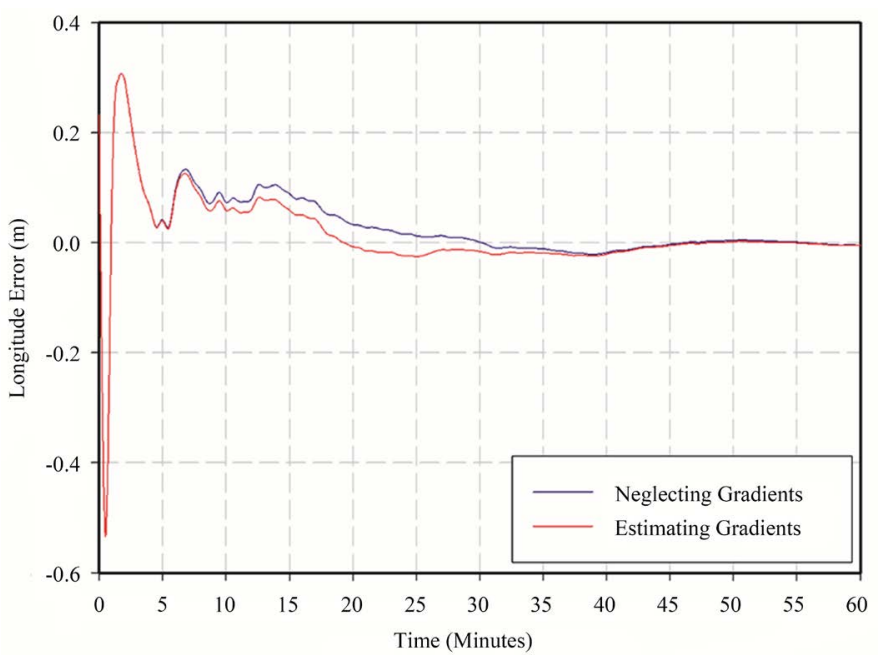

Figure 10. Effect of tropospheric gradients on longitude errors at KIRU IGS station.

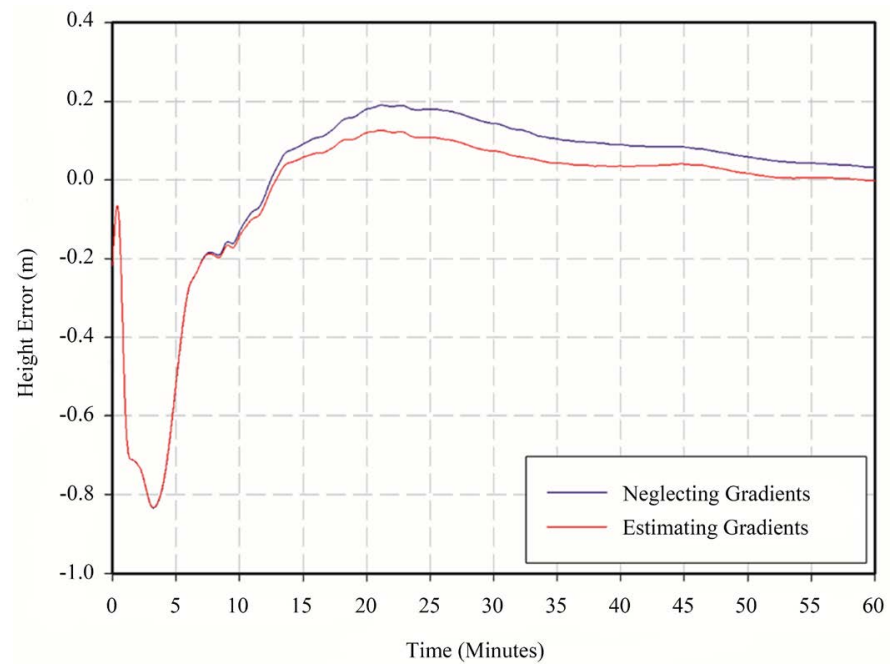

Figure 11. Effect of tropospheric gradients on height errors at KIRU IGS station. 
Table 2. Effect of tropospheric gradients on coordinates estimation.

\begin{tabular}{rcccccc}
\hline \multirow{2}{*}{$\begin{array}{l}\text { Time from } \\
\text { first epoch }\end{array}$} & \multicolumn{2}{c}{ RMS without tropospheric gradients $(\mathrm{mm})$} & \multicolumn{3}{c}{ RMS with estimation of tropospheric gradients (mm) } \\
\cline { 2 - 7 } & Latitude & Longitude & Height & Latitude & Longitude & Height \\
\hline 15-Minutes & 6.908 & 34.078 & 47.844 & 6.864 & 34.040 & 47.794 \\
30-Minutes & 4.153 & 18.837 & 27.204 & 4.133 & 18.679 & 26.689 \\
45-Minutes & 2.851 & 13.089 & 18.905 & 2.843 & 12.912 & 18.524 \\
60-Minutes & 2.168 & 9.973 & 14.346 & 2.165 & 9.842 & 14.056 \\
\hline
\end{tabular}

the coordinates of stations are kept fixed to their actual values and the tropospheric delay is estimated twice, with and without tropospheric gradients. In the second case, the station position is estimated along with the total tropospheric delay with and without tropospheric gradients. It is shown that the average bias of the estimated total tropospheric delay when neglecting tropospheric gradients ranges from $-1.72 \mathrm{~mm}$ to $2.14 \mathrm{~mm}$ while the average bias when estimating gradients are $-0.898 \mathrm{~mm}$ to $1.92 \mathrm{~mm}$ which means that the bias is reduced by about $30 \%$. In addition, the average standard deviation of the bias is $4.26 \mathrm{~mm}$ when the tropospheric gradients are estimated compared with $4.52 \mathrm{~mm}$ when the tropospheric gradients are neglected, which means that the standard deviation is improved by about 6\%. Moreover, the improvement in the estimated coordinates RMS is as low as 1 $\mathrm{mm}$.

\section{References}

[1] El-Rabbany, A. (2006) Introduction to GPS: The Global Positioning System. 2nd Edition, Artech House Mobile Communications Series. Artech House, Boston, xiv, 210 p.

[2] Misra, P. and Enge, P. (2006) Global Positioning System: Signals, Measurements, and Performance. 2nd Edition, Ganga-Jamuna Press, Lincoln.

[3] Kleusberg, A. and Teunissen, P.J.G. (1998) GPS for Geodesy. 2nd Edition, Springer, Berlin, New York, xiv, 650 p.

[4] Gutman, S., Fuller-Rowell, T. and Robinson, D. (2003) Using NOAA Atmospheric Models to Improve Ionospheric and Tropospheric Corrections. US Coast Guard DGPS Symposium, Portsmouth.

[5] Kouba, J. (2009) A Guide to Using International GNSS Service (IGS) Products. https://igscb.jpl.nasa.gov/igscb/resource/pubs/UsingIGSProductsVer21.pdf

[6] IERS Convention (2010) IERS Technical Note 36. http://www.iers.org/IERS/EN/Publications/TechnicalNotes/tn36.html/

[7] Morel, L., Pottiaux, E., Durand, F., Fund, F., Boniface, K., de Oliveira Junior, P.S. and Van Baelen, J. (2015) Validity and Behaviour of Tropospheric Gradients Estimated by GPS in Corsica. Advances in Space Research, 55, 135-149. http://dx.doi.org/10.1016/j.asr.2014.10.004

[8] Saastamoinen, J. (1972) Contributions to the Theory of Atmospheric Refraction. Bulletin Géodésique, 105, $279-298$. http://dx.doi.org/10.1007/BF02521844

[9] Davis, J.L., Herring, T.A., Shapiro, I.I., Rogers, A.E.E. and Elgered, G. (1985) Geodesy by Radio Interferometry: Effects of Atmospheric Modeling Errors on Estimates of Baseline Length. Radio Science, 20, 1593-1607. http://dx.doi.org/10.1029/RS020i006p01593

[10] Berrada Baby, H., Golé, P. and Lavergnat, J. (1988) A Model for the Tropospheric Excess Path Length of Radio Waves from Surface Meteorological Measurements. Radio Science, 23, 1023-1038. http://dx.doi.org/10.1029/RS023i006p01023

[11] Hopfield, H.S. (1969) Two-Quartic Tropospheric Refractivity Profile for Correcting Satellite Data. Journal of Geophysical Research, 74, 4487-4499. http://dx.doi.org/10.1029/JC074i018p04487

[12] Chao, C.C. (1971) The Tropospheric Calibration Model for Mariner Mars 1971. Technical Report 32-1587, 61-76.

[13] Herring, T. (1992) Modeling Atmospheric Delays in the Analysis of Space Geodetic Data. In: De Munck, J.C. and Spoelstra, T.A., Eds., Proceedirws of Refraction of Transatmospheric Simals in Geodesy, Geodetic Commission Publications on Geodesy, Netherlands.

[14] Niell, A.E. (1996) Global Mapping Functions for the Atmosphere Delay at Radio Wavelengths. Journal of Geophysical Research: Solid Earth, 101, 3227-3246. http://dx.doi.org/10.1029/95JB03048

[15] Boehm, J. and Schuh, H. (2004) Vienna Mapping Functions in VLBI Analyses. Geophysical Research Letters, 31, 
L01603. http://dx.doi.org/10.1029/2003gl018984

[16] Hofmann-Wellenhof, B., Lichtenegger, H. and Walse, E. (2008) GNSS Global Navigation Satellite Systems: GPS, Glonass, Galileo \& More. Springer Wien, New York.

[17] Leick, A. (2004) GPS Satellite Surveying. 3rd Edition, John Wiley and Sons, Hoboken.

[18] Elsobeiey, M. and El-Rabbany, A. (2014) Efficient Between-Satellite Single-Difference Precise Point Positioning Model. Journal of Surveying Engineering, 140, Article ID: 04014007. http://dx.doi.org/10.1061/(asce)su.1943-5428.0000125 